\title{
Institutional Dynamics and Participatory Spaces: The Making and Unmaking of Participation in Local Forest Management in India
}

\section{Ranjita Mohanty*}

\section{Introduction}

In recent times, we have come to witness many new forms through which the state has sought to engage people in processes of governance. Among them, the creation of local institutions for representation, deliberation and decision making at the village level is perhaps the most important. Seldom existing in isolation, these local developmental institutions intersect, interact and, at times, overlap with other local institutions. What shape participation eventually takes within these developmental spaces is thus contingent not only on the dynamics taking place within them, but also to a large extent on their relationship with coexisting local institutional spaces. This article explores the institutional dynamics within and between local institutions, for forest management in the hilly villages of Uttaranchal in northern India. Shaped by institutional procedures, by actors with affiliations and interests across other spaces, by competing perspectives on forest management and by a variety of forms of participation ranging from formal representation to employment to inclusion in deliberation and decision making, the dynamics of participation within spaces such as Uttaranchal's village forest protection committees (VFCs), is complex.

Creating and institutionalising spaces such as these, the article argues, provides necessary, but insufficient conditions to ensure the democratisation of participation. It shows how multiple versions of participation coexist within the spaces created by a single developmental project, in this case Joint
Forest Management (JFM). Practices, which treat people as beneficiaries, those which treat them as users/consumers who need to pay for the services, and those which make them citizens with the right to elect their representatives, demand transparency and accountability overlap and exist simultaneously. It is this complex intersection of normative ideals and practices which influences participation, as we encounter it in the villages of Uttaranchal.

Institutional spaces, I argue here, are vulnerable to contestations and conflicts of various kinds, which means participation does not remain a virtuous normative phenomena, though the normative desirability of participation remains unquestioned. Such spaces are never created in a vacuum, they react upon already existing spaces, on spaces which are simultaneous and overlapping and on the wider social-economic-cultural setting in which they are embedded. Even when they are created by exterior agencies, institutional spaces cannot be seen purely as an external or state creation. A certain amount of interest articulation, through overt or covert protest or through deliberation and negotiation, has generally gone into the shaping of what later comes as invited forums. Such spaces are constantly being created, altered, defined and redefined, with positive promise amidst manipulation, misuse and abuse. Even the most unpromising of institutions may open up possibilities for learning the skills and arts of governance, which people can use in other spaces. Spaces can emerge as arenas of solidarity as well as contestation, which may move between relative 
openness and closure over time. Lastly, whilst institutional spaces exhibit some of the dominant characteristics associated with "invited spaces" (Cornwall 2002; Gaventa 2002), they acquire characteristics of the setting in which they are located. As such, the article suggests, whilst these institutional spaces have the potential to create certain conditions for participation and democracy at the local level, they can also restrict its possibilities and therefore must not be conflated either with participation or with democracy.

\section{Multiple spaces in forest management}

Forests have been an integral part of the lives of people in the Kumaon region of Uttaranchal. People are dependent on forests for a variety of reasons: fuel for cooking, fodder for the animals, timber for house construction, medicinal herbs to cure ailments, and forest products such as resin have traditionally been the source of income. Currently, forest resources are managed by three types of local institutions, which are formed, supervised and regulated by the higher order government institutions to function as participatory fora. The focal institution at the village level is the van panchayat (forest panchayat). In recent years, van panchayats have been converted into VFCs under JFM schemes. Intersecting with these institutions is the gram panchayat (village panchayat), which forms the third tier of the governance system mandated by the Constitution of India. All these local institutions have a body of elected representatives who constitute the executive committee and are responsible for the administrative management of the funds, records and meetings. The executive committees are also the centres for decision making and have control over financial resources.

Regarded locally as the traditional system of forest management, van panchayats were originally created by the colonial administration and retain two essential traditional organising principles: the way representation from each hamlet is sought and mawasa, small monetary contributions made by each household to preserve the forest. The foundation was thus laid for "rights" to govern local institutional spaces for participation that were enforceable by law. Resentment raged in the colonial era against state control over forests (Guha 1991); records from this period reveal that people made claims on the state for the management of forest resources even when the language of rights was unfamiliar to them. The specification of management of forest in the language of rights, on the one hand, recognised certain ways of managing the forest; on the other, by specifying these rights, it delineated the content and boundaries of local action; what people were granted and allowed to claim and what they were not granted and, therefore, barred from. This not only restricted the local institutional management of forest to the civil/protected forest and limited access to reserved forests, it also specified what kind of actions were to be allowed in the institutional spaces created by the state for local participation.

In post-independence India, these institutions have persisted. Patterns established during the colonial regime remain unchecked, such as the practices that inhibited, if not purposefully restricted, the participation of certain kinds of people such as women, as voters, members, or even as participants in the village meetings. The very basis of these institutional spaces situated, and continues to situate, the state as giver of rights and the owner of the forest and the people as manager of only those areas which the state allowed. With this, the foundation was laid for the hierarchical relations between the state and its people found in today's institutional spaces.

\section{Dynamics of participation within VFCs}

The dynamics of participation taking place within the VFCs can be helpfully analysed through four variables: actors occupying the institutional space of VFC and their influence; competing knowledge/ perspectives on forest management; varieties of participation and the nature of engagement taking place within the VFC; and institutional procedures guiding the VFC and the management of resources, particularly financial resources and their allocation for forest management. For the purposes of this article, I focus in more depth on the first and third of these categories, in order to shed further light on the dynamics of voice, inclusion and influence in JFM.

\subsection{Actors and influence}

Of all the actors, the state is the most influential in the arena of forest management. Comprised as it is of heterogeneous, sometimes competing, 


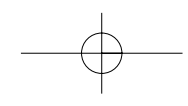

IDS Bulletin 35.2 New Democratic Spaces?

institutions, the state nonetheless has a central character, which is more overpowering and pervasive than the fragmentations and conflicts among those who represent it: as codified power, ultimate decision maker, resource mobiliser, the state impinges on the lives of people more than any other force, and determines how the affairs in society are to be managed. The role the state has played in the history of forest management has vested it with immense power. To understand people's subservience, it is important to understand the nature of the post-colonial state and the depth of people's relationships of dependence and patronage with the state. It is important to capture how the state features in the imagination of people, since it is their relationship with the state, ranging from disillusionment and despair to seeing it as a patron and a benefit, which reflect in their relationship with the state-created institutions. We find them unhappy with the way the Forest Department and the Revenue Department manages the JFM, but with a strong belief that the JFM project as well as the VFC as an institution, are inherently beneficial and that, where good officers are in charge, the project can deliver the desired good. Thus state mismanagement and authoritarianism are considered merely an anomaly, a reflection of the idiosyncrasies of specific officers.

Though JFM is said to be based on the principles of participation and shared responsibilities, in reality the Forest Department has simply carved out a bigger role for itself and made the VFC dependent on it for planning and inflow of finances; the forest guard is the member secretary of the VFC and has the power to operate the JFM bank account jointly with the sarpanch. The control, therefore, still rests with the Forest Department. In the village of Soan Gaon, financial embezzlement by the forest guard led to distrust in the VFC, which eventually became the victim of apathy of the Forest Department, who stalled the project in order to hide their own fault. Soan Gaon may be an extreme example, but the lack of autonomy in planning and financial matters has made many VFCs disinterested in taking responsibilities for forest management.

The local institutional space is the locus of power and can patronise those who enjoy the decisionmaking powers in these institutions. As they are the close allies of the state, the power of the state is transmitted to them and through them to the institutional space. This power is manifested in being able to manage finances, write reports, maintain accounts, organise meetings and distribute work. Decisions are often taken in closed-door meetings, or they are taken with the forest guard and the Divisional Forest Officer (DFO) and later approved in village meetings. The sarpanch or the influential panchas try to do maximum work related to plantation in their own toks so that people there can benefit. Below this layer come people who hold other forms of status, whether from their social standing such as teachers or the ex-sarpanch, or from their economic position, or as a result of political lobbying. The influence these actors exert is both positive and negative. They give direction to decision makers and can counterbalance state interference; but they also have the potential to exercise their own influence to exploit forests and alienate those in most need from forest management.

At the end of the spectrum come people who are the most dependent on forests economically. They hold the least political power and may not have any social standing, particularly if they belong to lower castes, and would be alienated from the public space if they are women. This category is the most vulnerable to external influence, whether by the state or by others in the village. However, they are not completely powerless. While others exercise a lot of visible power, this category has its own ways of resistance and dealing with the powerful. One of the potent methods of resistance is refusal to provide labour. Since most of these people are wage labourers, their refusal sends a signal of resistance. This refusal does not paralyse the employer so much economically as it does politically, because the opponent either voluntarily seeks patronage of the rival fraction or is invited to join it. Gossip remains another form of resistance, often centring on the misappropriation of funds by the sarpanch or other members of the panchayat. These 'weapons of the weak' and 'hidden transcripts' (Scott 1990, 1998) turn spaces for participation into arenas of contestation rather than solidarity and warmth. The more people remain outside the space, the more exclusive the space becomes.

\subsection{Competing knowledge/perspectives}

It may sound paradoxical that people could also resent control by the same state that they otherwise venerate. But historical evidence reveals resentment of the extension of state control over forests, in 
different periods. ${ }^{1}$ As mentioned earlier, the colonial period saw violent protests against the British administration when it tried to alienate people from the forests. Subsequently, resentment centred on the overwhelming presence of the Revenue Department in local village forest management, its strict control over van panchayat funds, and the high-handedness of the forest guard, who created perpetual fear of him lodging false complaints. With JFM, part of the reserved forest has come within the purview of the VFC. But people know that once the project period is over, it will return to the control of the Forest Department. Even the ownership and control over local forest, with the management of which the van panchayat is entrusted, lies with the Revenue Department. This turns people into mere managers of forests owned by the state. Thus deep down resentment against the state simmers.

Negation of the willingness to manage forests in favour of the technical expertise to manage has become more pervasive under JFM. Fund management, accounts-keeping and, above all, understanding the technicalities and complexities of the project favours people who are literate. Hence, despite all the supposedly good principles of participation which JFM promotes, in reality it discriminates those who are illiterate. There is hardly any scope within the project frame to accommodate people who may not understand the technicalities of the project, but are bestowed with local wisdom, willingness, commitment and spontaneity to look after their forest resources.

\subsection{Dimensions of participation}

In the pre-colonial period, abundant forest and low population pressure left access to forest resources relatively unfettered. By turning the forest into a commercially viable resource, the colonial state restricted people's engagement with the management of forest resources. The constitution of van panchayats and the recognition of certain rights over the forest, as mentioned earlier, gave participation a formal, legal and institutional shape. Participation of the people thereafter was confined to voting in the elections of the van panchayat and abiding by the rules which governed the panchayati forest. In this system of forest management, women seldom participated either as voters or as members of the panchayat committee; they seldom attended the panchayat meetings. Many van panchayats became defunct over the years due to lack of funds, lack of interest by the Revenue and Forest Departments and unresolved village conflicts. JFM gave the van panchayats a new lease of life, as VFCs activated and empowered them in a variety of ways.

Poor people's participation in forest management under JFM has been synonymous with employment. JFM, following the general pattern of development projects, emphasises contributions in the form of labour. A certain percentage of their wage goes to the village development fund (VDF), supposedly to promote a sense of ownership. In an economic setting with few employment opportunities, project work, such as plantation, check-dam construction, etc., is sought after by poor people. In all villages studied, people cited the period of project-related employment as the time when meeting attendance is larger and more regular than at any other time.

Given economic realities, project work does help poor people, but their sense of involvement like their employment in the project remains temporary. Hence, once the project is completed, there is little further involvement. Their consciousness regarding conservation of natural resources does not translate into action. Since their involvement in the project and their understanding of the role of the VFC remains inadequate, their sense of ownership of the project lasts till the project ends. This is evident in their thin presence in meetings after the project work is completed and disagreements with the VFC regarding the nature of proposed VDF expenditure. In fact, and ironically so, a large number of people whose contribution has gone to build the village fund are not even aware that a portion of their wage is kept in the fund.

As a representative body of people the VFC itself stands for and signifies people's participation. But alongside that, it is required to seek wider participation and engagement of the people. The provision for reservation of seats for the lower castes and women has given them a formal place in the decision-making forum of the VFC. In practice, however, the inclusion of women often becomes dependent on government officials and the sarpanch. In Deeni and Saladi, women have got membership in the VFC because forest officials as well as the sarpanch were keen on including them. Parwarda was the only exception where the sarpanch was a woman and therefore, could take a lead role in the VFC. In a village setting, which has never been inclusive of people low in social and economic position, the public space remains restrictive. 


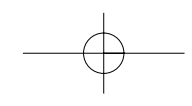

IDS Bulletin 35.2 New Democratic Spaces?

\subsection{Institutional procedures}

The supervisory and regulatory procedures of the state affect participation in many ways. Under JFM, the VFCs have been superimposed on van panchayats and the lack of coordination between the two government departments responsible for the formation of these institutions and their supervision has filled the space with conflicts. Though existing van panchayats are converted into VFCs, the VFCs are not allowed to utilise the van panchayat fund during the JFM period. This has restricted their activities, because funds can only be spent on activities mentioned in the micro-plan. While the VFCs largely have to work with the Forest Department, the responsibility of VFC elections still lies with the Revenue Department. The lack of departmental coordination has implications for VFC functioning. Van panchayats have a five-year duration whereas the VFCs have a four-year duration. Some VFCs, if they go by van panchayat directives, would need fresh elections even during the implementation of JFM. There is no understanding among the two departments as to the conditions for fresh elections. All this makes long-term planning for the VFCs difficult and at the village level, VFC members also lack interest in sustaining the committee beyond JFM.

\section{Presence, influence and voice: women in JFM}

To what extent, then, does JFM actually extend the new opportunities for involvement and voice of more marginalised actors that it promises? What does participation actually come to mean? And, how do less vocal people, such as women, engage with the spaces for participation that JFM makes available? Taking the case of women's participation, some of the paradoxes of participation in JFM become evident.

In earlier times, there was little participation by women either as voters or decision makers in the van panchayats. With the advent of JFM, there was an emphasis on bringing women, the primary users of the forest, into the centre of forest management. The critical question, however, remains "how"? How will women, who have hitherto remained confined to the private spaces of household, enter public space? How will their wisdom find a place in decision making? Will they be able to raise their voice in a meeting where they relate to male members as fathers, husbands, fathers-in-law; relations they are expected to revere and not question?

Talking to women in the hilly villages of Uttaranchal revealed the tension that underlies their trying to break with the status quo. One woman from Jungaliya Gaon spoke for many when she said, 'it is like a risky walk on the rope. We do not want to displease the male members, but at the same time we do not want to lose out on the opportunity of coming out of the house and being part of the processes taking place in the village'. Is there any backlash they face? 'Yes, sometimes, but gradually and also due to the constant encouragement of the DFO saab, things have improved'. While the project makes it mandatory that a certain percentage of women must be present in the VFC executive committee, a great deal is left to the goodwill of the VFC head, who is usually a male; to the forest bureaucracy, also usually male; and of course to the goodwill of male members of her family. Without any effective institutional mechanism to ensure participation of women, their involvement remains piecemeal and subject to the mercy of men, whether husbands, forest bureaucrats or committee members.

Even when women do find a place in the decision-making body, they seldom speak. The mere presence of women in decision-making spaces does not guarantee that their voices will be raised, heard or have an impact. It is naive to expect that spaces, which have hitherto remained exclusive, will open up and become inclusive, by merely giving women a formal place. The reason for women not being able to speak, or their voices not getting heard are many. They include the cultural barriers of not speaking in front of elderly male members of the family or the village and the patriarchal system in which women seldom occupy public space, or are even recognised as being capable of taking a public decision. ${ }^{2}$ As Ganga Joshi reflected,

... it is much easier to organize women's collectives where they can speak uninhibited. But then that is not what women's participation in the long run should look like. If they have to be integrated into the wider process, we have to face the challenge of enabling them to speak in a forum which is not exclusively for women. (pers. comm.)

Women tend to be complacent, arguing that whatever decision their fathers, husbands or other 
male members in the family or village ask them to take, will eventually prove beneficial. This hides the critical and dangerous consequence that their mere presence without voice can be used to legitimise decisions.

Without much of a presence or voice in decisionmaking arenas, village women are expected to participate in public meetings related to local forest management. Due to usual household work, which includes collection of fuel and fodder and assisting men with farm activities, women's time is scarce. The arena in which women are most active is in implementation, yet their predominance here raises concern about issues of equity and about the relationship between the spaces of participation of implementation and those in which management decisions are taken. Women are often employed as members of the safety squad to guard the forest against illegal lopping or encroachment. This helps them earn extra income for the family, but also burdens them. They have to patrol the forest at night, which means there is hardly any time left for them to rest. While the entire household benefits from the forest resources, men take all the important decisions regarding forests and women continue to take the burden of their protection. And while women face daily harassment from the forest officials and find many ways to negotiate with them, when it comes to decision making with regard to forest management issues, they are systematically pushed to the margins (Agarwal 1997; Sarin 1998).

Other spaces outside the public sphere in which women can gain confidence, skills and a sense of their own capabilities prove significant in enabling women to engage in forest management activities (Agarwal 1997). Women's participation has been enhanced in those villages where there is an already existent forum and space for women created either by voluntary organisations such as the Central Himalayan Rural Action Group (CHIRAG) in the form of Van Suraksha Samiti (VSS), women's collectives formed for afforestation activities, or by government in the form of Mahila Mangal Dal (MMD) women's collectives formed to integrate them with various state-led developmental interventions. This has helped in spreading awareness and fostering a spirit of engagement amongst women. Before JFM was introduced in the villages, there was an effort to organise and mobilise women towards common management of forest resources. This created space for social and participatory engagement, making it easier for VFCs to seek wider participation in the village. It is interesting to note that these spaces always remained outside the spaces created by the government exclusively for the purpose of forest management. Where women (limited though such cases are) have been linked in a sustained and integrated manner with the project as in the villages of Saladi and Deeni, new leadership has emerged. With it has come new-found confidence that is visible in many ways: in meetings, in articulating issues, in dealing with the project authorities. The involvement of women has enhanced the quality of participation. The space that had hitherto been denied to women has become more open and participatory, though it also remains restrictive, given women's existing workload.

\section{Conclusions}

Currently available spaces for people to participate in the management of their local forests in Kumaon are the result of a series of transformations that earlier spaces have gone through, from informal practices of forest management to van panchayats, and from van panchayats to VFCs. In the process of superimposition of one institutional space over another, some bits of the previous space were always carried into the new space. So what we find at the local level today is a combination, in varying degrees, of traditional practices, state-given conceptions of rights, the principles of normative and participatory democracy, as well as the instrumentalities behind the promotion of participation. The spaces, therefore, are for negotiating rights and claiming entitlement; they are also spaces for influencing governance and connecting with the state as citizens. JFM has projectised participation and turned it into employment. The state still holds regulatory power over the VFCs. The instrumentalities of participation have not been abandoned completely. But limited as these spaces are, there is also no denying that they have created opportunities for marginalised groups to play a part in decision making. So, even if the landscape of marginalisation is not completely altered, new leadership is emerging from marginalised sectors of society, from women, from lower castes. By acquainting people with the language of the state and through engagement with state-led rules, JFM has taught people the art of governance, however rudimentary that may appear. 


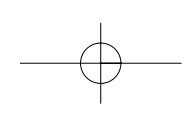

IDS Bulletin 35.2 New Democratic Spaces?

Spaces created for participation in forest management are influenced as they intersect with other institutional spaces, both those created by civil society organisations and other, more informal, arenas. When they intersect with supportive spaces, they become open, intimate, and inclusive and when they intersect with conflicting spaces, they become closed and exclusive. The dynamic interplay of power, which links various institutions and institutions with wider society, turns spaces into negotiating fields and participation into an essentially political act. Who comes into the space, who takes decisions, whose voice counts, who is left at the margins then depends not only on how power operates in that particular space, but also how it operates between different state institutions, between the state and people, among various groups in the village having differential positioning in the society and among groups having different institutional affiliations. In this process of negotiation, there is always the possibility of the marginalised, vulnerable sections being excluded from decision making. Given their transformatory nature, the conflicts and contestations which fill them and the power dynamics which influence them, these spaces remain complex and contested. Necessary, but not sufficient to foster participation, however open these spaces may be, they need to be constantly guarded, particularly by those who are most vulnerable and are more likely than others to be left at the margin.

\section{Notes}

* I am most thankful to Ganga Joshi from CHIRAG, without whom the study could not have taken the shape it eventually did. Ganga not only accompanied me on the arduous hilly roads of Uttaranchal; she also introduced me to the multifaceted local culture and pahadi ways of life. I benefited immensely from her insights, her professional contacts and her social ties. Thanks, Ganga, for all your help in completing the study.

1. I have already cited the protest during the British administration. After independence, the Chipko movement, the movement by people, particularly

\section{References}

Agarwal, B., 1997, 'Re-sounding the alert - gender, resources and community action', World Development, Vol 25 No 9: 1373-80

Bhatt, C.P., 1991, 'Chipko movement: the hug that saves', Survey of the Environment, The Hindu: $17-23$

Cornwall, A., 2002, 'Making spaces, changing spaces: situating participation in development', IDS Working Paper 170, Brighton: Institute of Development Studies

Gaventa, J., 2002, 'The use of power in framing and shaping the spaces, places and dynamics of participation: a discussion note', mimeo, Brighton: Development Research Centre (DRC) Workshop, 22-24 October

Guha, R., 1991, The Unquiet Woods: Ecological Change and Peasant Resistance in the Himalayas, Delhi: Oxford university Press

women, in the hills, who resisted the commercial felling of trees by hugging them, revealed the tenuous relationship between the people and the state in matters related to the use and control of forests. See Guha (1991), Bhatt (1991) and Shiva (1988).

2. Citing the case of women's participation in the VFC in Gonduru village in Uttar Kannada, Sunder et al. (2001) write, 'as a "daughter of the village" she could voice her opinion, but once she became a "daughterin-law of the village", moreover, one married into the chairperson's household, her freedom to speak in front of family and village elders was severely curtailed' (2001: 114)

Sarin, M., 1998, 'Community forest management: whose participation?', in I. Guijt and M.K. Shah (eds), The Myth of Community: Gender Issues in Participatory Development, London: Intermediate Technology Publications

Scott, J., 1998, Seeing Like a State, New Haven: Yale University Press

Scott, J., 1990, Dominance and the Arts of Resistance: Hidden Transcripts, New Haven: Yale University Press

Shiva, V., 1988, Staying Alive: Women, Ecology and Development in India, Delhi: Kali for Women

Sunder, N., Jeffrey, R. and Thin, N., 2001, Branching Out: Joint Forest Management in India, Delhi: Oxford University Press 